\title{
Dinâmica em Barras Viscoelástica
}

\author{
Frossard, A. L. C.; Loeffler C. F. \\ Programa de Pós-Graduação em Engenharia Mecânica, Universidade Federal do Espírito Santo, Vitória, ES, Brasil
}

\begin{abstract}
Resumo
Normalmente nos projetos rotineiros de engenharia costuma-se trabalhar com materiais que apresentam um comportamento mecânico constitutivo independente do tempo. No entanto, com a evolução dos materiais e a inclusão de polímeros dentre os materiais usados na construção em engenharia, tornou-se importante incluir o efeito da dependência do tempo no comportamento destes materiais quando submetidos a uma dada carga. Entre os muitos efeitos, encontram-se os efeitos viscosos de relaxação, fluência e deslizamento. Por outro lado, muitos problemas da engenharia moderna envolvem carregamentos dinâmicos, de modo que os modelos matemáticos resultantes são complexos por acoplar simultaneamente o caráter dependente do tempo da resposta e do material constitutivo. Para resolvê-los, métodos numéricos discretos têm sido desenvolvidos, com formulações específicas para a sua abordagem, o que requer soluções analíticas para melhor aferição da qualidade de seus resultados. Com o intuito de gerar tais soluções de referência, este trabalho apresenta a solução analítica de uma barra visco elástica sujeita a uma carga de impacto, através do tradicional Método de Separação de Variáveis.
\end{abstract}

Palavras-chaves: Materiais visco elásticos, Método de Separação de Variáveis, Soluções Analíticas de Referência.

\section{Introdução}

O estudo e utilização de polímeros como material de construção mecânica ainda possui relativamente pouca aplicação em engenharia. Entre as razões que podem ser justificadas, existe a questão da complexidade do modelo matemático e também o fato de não haver ainda uma formação cultural sobre suas propriedades e vantagens funcionais, pois são mais leves, tem boa absorção de impacto e fácil maleabilidade. Nesse artigo, busca-se mostrar a utilização do modelo viscoelástico de Maxwell, adaptado para montar uma equação característica voltada a materiais que apresentam esse comportamento e possuem cargas dinâmicas aplicadas, visto que a engenharia moderna, sobretudo a Mecânica, trabalha usualmente com equipamentos rotativos de alta velocidade nos quais atuam cargas dinâmicas significativas. A solução apresentada no texto é um exemplo de uma barra polimérica solicitada por uma carga de impacto, que é um problema simples, mas elucidativo, das particularidades que cercam a modelagem matemática destes materiais.

\section{Modelo Matemático}

Para construção considera-se um sólido de Maxwell adaptado [1], em que uma mola e amortecedor em série estão em paralelo com uma mola auxiliar, conforme apresenta a figura 1 :

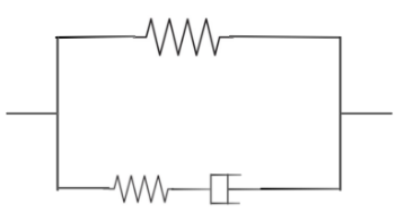

Figura 1: Modelo de Maxwell adaptado.

Neste caso, a equação que relaciona tensão e deformação é dada por [3]:

$\frac{\partial \sigma}{\partial t}=E \frac{\partial^{2} u}{\partial x \partial t}-\frac{\sigma}{\tau}$

Onde $E^{*}$ é o módulo de elasticidade resultante das molas, $\boldsymbol{\sigma}$ é a tensão inicialmente aplicadas, $\boldsymbol{\tau}$ é o tempo de relaxamento do material e $u$ representa $o$ deslocamento ao longo da direção x. A segunda lei de Newton neste caso é expressa por [4]:

$\rho \frac{\partial^{2} u}{\partial t^{2}}=\frac{\partial \sigma}{\partial x}$

Compondo estas duas equações, a equação diferencial parcial que governa a propagação de ondas axiais é representada por:

$\rho \frac{\partial^{3} u}{\partial t^{3}}-E^{*} \frac{\partial^{3} u}{\partial x^{2} \partial t}+\frac{\rho}{\tau} \frac{\partial^{2} u}{\partial t^{2}}=0$ 
Ressalta-se que neste modelo o comportamento elástico e dissipativo estão em paralelo. A solução desta equação pode ser obtida considerando-se que:

$\rho \frac{\partial^{2} u}{\partial t^{2}}-E^{*} \frac{\partial^{2} u}{\partial x^{2}}+\frac{\rho}{\tau} \frac{\partial u}{\partial t}=\gamma$

O valor de gama é retirado da análise das condições de segunda derivada no tempo e depende das propriedades viscoelásticas do material.

\section{Solução}

Obtida através do Método de Separação de Variáveis [5] pode-se resolver a equação anterior considerandose que a constante apresentada no lado direito da igualdade comporta-se como uma ação de domínio. Admitindo que o sistema consista de uma barra engastada numa extremidade, a solução pelo citado método fornece:

$u(x, t)=\frac{P}{E} x+\sum_{n=1,3,5}^{\infty}-\frac{2 P L}{(n \pi)^{2} E} * \operatorname{sen}\left(\frac{n \pi}{2 L} x\right) *$

$e^{-\frac{1}{2 \tau} t}\left[\cos \left(\sqrt{\left(\frac{n \pi}{2 L}\right)^{2} \frac{E}{\rho}-\frac{1}{4 \tau^{2}}} t\right)\right]$

A solução foi obtida considerando materiais que apresentam movimento oscilatório e amortecido: portanto, deve-se satisfazer a seguinta condição:

$\left(\frac{n \pi}{2 L}\right)^{2} \frac{E}{\rho}>\frac{1}{4 \tau^{2}}$

A representação gráfica dos deslocamentos ao longo do tempo é similar ao de um problema de impacto amortecido, figura 2. Neste caso, toma-se um material similar ao utilizado em [2], com tempo de relaxamento de $0,4(1 / \mathrm{s})$, densidade 20 e módulo de elasticidade $1280 \mathrm{KN} / \mathrm{cm}^{2}$. A carga é de $1 \mathrm{KN}$ e o comprimento da barra é de $10 \mathrm{~cm}$.

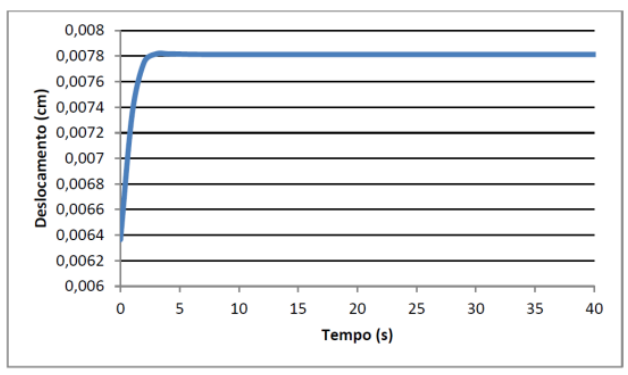

Figura 2 - Gráfico Deformação versus tempo, resultado da aplicação das propriedades na equação (5). Fonte: autoria própria.

O resultado encontrado por [2] é semelhante ao encontrado na figura 2 , sendo necessário ressaltar que na referência citada foi utilizada uma barra de $100 \mathrm{~cm}$, que não foi adotada aqui por não satisfazer a (6), embora ofereça uma boa comparação qualitativa, vide figura 3.

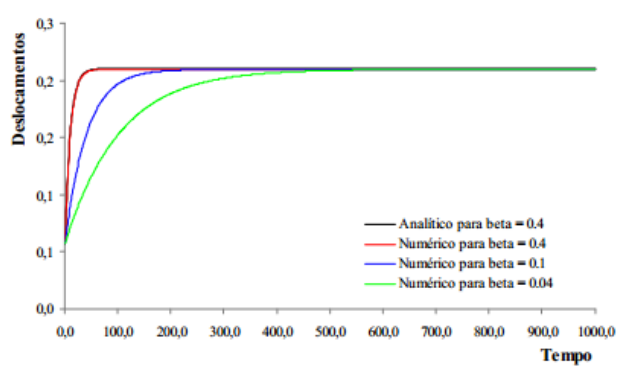

Figura 3: Resultado obtido em [2] para o deslocamento na direção x, a solução analítica é a curva em preto, bem próxima à vermelha. [2]

\section{Conclusões}

A modelagem do problema em questão aponta uma similaridade com os problemas elásticos simples em que ações de domínio atuam no sistema, como, por exemplo, a carga gravitacional. Entretanto, esta condição é obtida por imposição de condições iniciais referentes à inércia do sistema no instante da aplicação do carregamento dinâmico, e precisa ser generalizada para casos mais complicados. De qualquer modo, tais soluções servem para embasar os pesquisadores no desenvolvimento métodos numéricos, em que é preciso contar com soluções analíticas para exame da qualidade dos seus resultados. Assim, com a difusão desse tipo de conhecimento e ampliação das técnicas de solução de problemas, os engenheiros e físicos poderão se motivar a desenvolver e utilizar polímeros em seus trabalhos, o que amplia a quantidade de materiais para opção na construção e empreendimentos em geral.

\section{Referências}

[1] E. Kreiszig, Matematica Superior, vol3, Livros Técnicos e Científicos Editora, Rio de Janeiro, 1976.

[2] F.Cezario, Uma Formulação para o Método dos Elementos de Contorno Aplicada a Problemas Viscoelásticos Lineares, Quasi-Estáticos e Dinâmicos, no Domínio do Tempo, UFRJ/COPPE (Tese de Doutorado no Programa de Engenharia Civil), Rio de Janeiro, 2009.

[3] H. Kolsky, "Stress Waves in Solids", Dover, 1963.

[4] R. M. Caddell, "Deformation and Fracture of Solids", Prentice-4Hall, 1980.

[5] R. C. Juvinall, "Engineering Considerations of Stress, Strain and Strength", McGraw-hill, 1967. 